\title{
Thrombotic thrombocytopenic purpura preceding systemic lupus erythematosus
}

\author{
Carmen Pilar Simeon-Aznar, Rafael Cuenca-Luque, Vicente Fonollosa-Pla, \\ Jose Angel Bosch-Gil
}

\begin{abstract}
The case of a patient admitted with thrombotic thrombocytopenic purpura nine years after developing systemic lupus erythematosus (SLE) is reported. Thrombotic thrombocytopenic purpura associated with SLE has been described on other occasions, but in most patients the diagnosis of SLE precedes that of thrombotic thrombocytopenic purpura. The unusual sequence and the chronological separation of the two diseases is emphasised.
\end{abstract}

Thrombotic thrombocytopenic purpura is a rare clinical syndrome characterised by the presence of microangiopathic haemolytic anaemia, thrombocytopenic purpura, neurological abnormalities, fever, and renal dysfunction. ${ }^{1}$ In most patients there is no known aetiological agent or related underlying disease. On rare occasions, thrombotic thrombocytopenic purpura has been described in association with systemic lupus erythematosus (SLE). $^{23}$ A relation between SLE and thrombotic thrombocytopenic purpura has not been shown; however, similar clinical features may be observed in the two diseases. Chronologically, thrombotic thrombocytopenic purpura presents in patients previously diagnosed with SLE. ${ }^{3-12}$ An inverse sequence of events is rare. ${ }^{2} 13$ A patient who presented with thrombotic thrombocytopenic purpura and who then developed SLE nine years later is described in this paper.

\section{Case report}

A 30 year old woman with no relevant medical history was admitted in January 1980 with general weakness, headache, jaundice, and petechiae. Physical examination also revealed skin amd mucous membrane pallor and hepatosplenomegaly.

A chest radiograph was normal. Laboratory data included severe anaemia with haemoglobin $70 \mathrm{~g} / 1$ (normal $<120 \mathrm{~g} / \mathrm{l}$ ), packed cell volume $0 \cdot 2$, abundant schistocytes, platelet count $17 \times 10^{9} / 1$ (normal $\left.150-450 \times 10^{9} / 1\right)$, direct bilirubin $136.8 \mu \mathrm{mol} / 1$ (normal $6.84 \mu \mathrm{mol} / 1$, haptoglobin $0 \mathrm{~g} / \mathrm{l}$, and reticulocyte count $250 \times$ $10^{9} / 1$ (normal $\left.<75 \times 10^{9} / 1\right)$. Coagulation tests were normal. Coombs' and sucrose lysis tests were negative. A test for antinuclear antibodies was positive at a titre of $1 / 100$; antibodies to double stranded DNA were negative. The Venereal Disease Research Laboratory (VDRL) test was negative.

On the fourth day of admission, the patient developed fever and suffered transient left hemiplegia. On suspicion of thrombotic thrombocytopenic purpura, gingival and skin biopsies were performed with non-specific results. Treatment with methylprednisolone $(100 \mathrm{mg} /$ day), platelet antiaggregants (aspirin $600 \mathrm{mg} /$ day and dipyridamole $30 \mathrm{mg} /$ day), and fresh plasma transfusion was started. The patient failed to respond to treatment and after two weeks she developed a left hemiplegia and went into deep coma. Laboratory data showed impaired renal function (creatinine 282.88 $\mu \mathrm{mol} / \mathrm{l})$. Computed tomography of her brain was normal. Plasmapheresis was started (10 sessions in 20 days, $12 \mathrm{U}$ per session) and a progressive improvement in the level of consciousness and motor deficit was observed from the fourth day onwards. The patient was discharged three months after admission with a diagnosis of thrombotic thrombocytopenic purpura in complete remission.

In June 1989, nine years after her first admission, the patient was admitted to hospital with symmetric polyarthritis, fever and malaise of five months' duration. Physical examination revealed hepatosplenomegaly and synovitis of the hands, knees, and ankles. Laboratory data included: erythrocyte sedimentation rate 35 $\mathrm{mm} /$ hour (normal $<15 \mathrm{~mm} /$ hour); haemoglobin $90 \mathrm{~g} / \mathrm{l}$, leucocytes $2.5 \times 10^{9} / 1$ (normal 5-8 $\left.\times 10^{9} / 1\right)$ with lymphocyte count $\left(0.7 \times 10^{9} / 1\right.$ (normal $\left.1 \times 10^{9} / 1\right)$, platelet count $196 \times 10^{9} / 1$, creatinine $167.96 \mu \mathrm{mol} / \mathrm{l} ; \mathrm{C} 3$ and $\mathrm{C} 4$ fractions were low (C3 $520 \mathrm{mg} / \mathrm{l}$, normal $850-1700 \mathrm{mg} / \mathrm{l}$; C4 70 $\mathrm{mg} / \mathrm{l}$, normal $90-400 \mathrm{mg} / \mathrm{l}$ ). Urine analysis showed proteins in urine at $750 \mathrm{mg} /$ day and urine sedimentation with 30 red cells per field. Coagulation tests were normal. A test for antinuclear antibodies was positive at a titre of 1/2560 with a speckled pattern; antibodies to double stranded DNA could now be seen at 139 $\mathrm{U} / 1$ (normal <15 U/l). Anticardiolipin antibodies and lupus anticoagulant were negative. Sucrose lysis and Coombs' tests were negative. A renal biopsy sample revealed diffuse proliferative glomerulonephritis. A diagnosis of SLE with renal involvement was made and treatment with methylprednisolone $(60 \mathrm{mg} /$ day $)$ and bolus cyclophosphamide (15 $\mathrm{mg} / \mathrm{kg} /$ day) was initiated. The patient improved with this treatment.

\section{Discussion}

The diagnosis of thrombotic thrombocytopenic purpura is usually based on the clinico-biological syndrome (microangiopathic haemolytic anaemia, thrombocytopenic purpura, neuro- 
logical abnormalities, fever and renal dysfunction ${ }^{1}$ ) presented by the patients. There are several similarities between the clinical features of SLE and thrombotic thrombocytopenic purpura which present certain difficulties at the time of diagnosis, although in most patients differential elements point to one pathological disease or the other. In SLE, microangiopathic anaemia, usually associated with diffuse vasculitis or malignant hypertension, may rarely be detected. ${ }^{3}$ Negativity or normality of SLE immunological markers (antibodies to DNA, Coombs' test or complement) support the diagnosis of thrombotic thrombocytopenic purpura in doubtful instances, although non-SLE associated positive antinuclear antibodies have been found in some patients with thrombotic thrombocytopenic purpura. ${ }^{15} 14$ The finding of characteristic pathological features in a gingival biopsy sample confirms the diagnosis of thrombotic thrombocytopenic purpura, but their absence does not rule it out. In a recent review, only $39 \%$ of biopsies performed gave specific results. ${ }^{15}$ The clinical and analytical manifestations presented by our patient on the first admission, the remission obtained with plasmapheresis, and the lack of criteria for the diagnosis of SLE confirm the diagnosis of thrombotic thrombocytopenic purpura.

Triggering factors of thrombotic thrombocytopenic purpura include toxic agents, infections and drugs, although in most patients $(90 \%)$ there is no apparent cause. ${ }^{1}$ The association of SLE and thrombotic thrombocytopenic purpura is rare. In the review of Ridolfi and Bell $^{1}$ of 250 patients with thrombotic thrombocytopenic purpura, only three met the presently accepted criteria for SLE. ${ }^{16}$ Isolated patients with thrombotic thrombocytopenic purpura and SLE were later described. ${ }^{3}$ 8-12 In the series of Levine and Shearn, ${ }^{7} 34$ of 151 patients (23\%) presented signs and symptoms suggestive of SLE. Clinical information available on these patients was incomplete and did not fulfil the American Rheumatism Association 1982 revised criteria for the diagnosis of SLE. ${ }^{16}$ There are only three reported patients in whom the diagnosis of thrombotic thrombocytopenic purpura preceded the development of SLE. ${ }^{2}{ }^{13}$ However, the diagnosis of SLE in these patients was based on pathological findings (LibmanSacks endocarditis, glomerulosclerosis, periadventitial splenic fibrosis), which suggested a 'lupus-type' disease; the strict application of present criteria places the diagnosis in doubt. On her second admission, our patient, apart from presenting no signs of thrombotic thrombocytopenic purpura, fulfilled sufficient criteria for the diagnosis of SLE (arthritis, leucopenia, diffuse proliferative glomerulonephritis, high antinuclear antibody titres and increased antibodies to double stranded DNA).

To establish a pathogenic relation between thrombotic thrombocytopenic purpura and SLE, various hypotheses have been suggested; however, the precise mechanism is still to be defined. Patients with SLE may present alterations of coagulation and thus be at greater risk of thrombosis. ${ }^{17}{ }^{18}$ Some patients with SLE who developed thrombotic thrombocytopenic purpura had a previous history of thrombophlebitis. ${ }^{511}$ On the other hand, an immunological connection between the two diseases has not been identified, as patients with SLE who present with thrombotic thrombocytopenic purpura during a clinical or immunological flare of their disease have also been described. ${ }^{511}$ The development of thrombotic thrombocytopenic purpura during remission of SLE has also been reported. ${ }^{4}$ It has recently been suggested that thrombotic thrombocytopenic purpura may play a pathogenic part in central nervous system alterations in SLE. ${ }^{19}$ A necropsy study of 50 patients with neurological manifestations of SLE showed pathological central nervous system alterations in $50 \%$ of patients. In the final stages of their disease, 14 patients presented a clinical syndrome of thrombotic thrombocytopenic purpura; in half of these pathological thrombotic thrombocytopenic purpura changes in the central nervous system (occlusion of arterioles and capillaries with platelet-fibrin thrombi, segmental subendothelial hyalin deposits, and arteriolar microaneurysms) were observed. In ten of the remaining patients, cerebral infarctions secondary to embolism of cardiac origin (Libman-Sacks endocarditis in five, chronic valvulitis in two, heart mural thrombus in two), were reported. No vasculitic lesions were observed in any of the patients. These authors ${ }^{19}$ suggested that thrombotic thrombocytopenic purpura lesions and endocarditis were common pathogenic factors in central nervous system alterations in SLE. No coagulation studies were performed in most of these patients; however, many may have had an 'antiphospholipid syndrome'.

We believe that our patient differs from others previously reported, not only in the unusual chronological sequence of presentation, but also in the difficulty encountered in establishing a correlation between thrombotic thrombocytopenic purpura and SLE, given the long period of time in which the patient was asymptomatic and the clinical presentation of the two diseases in the same patient.

The authors thank Christine O'Hara for her help with the English translation of this paper.

1 Ridolfi R, Bell W. Thrombotic thrombocytopenic purpura Report of 25 cases and review of literature. Medicine (Baltimore) 1981; 60: 413-28.

2 Beigeliman P M. Variants of the platelet thrombosis syndrome and their relationship to disseminated lupus. Arch Pathol 1951; 51: 213-23.

3 Gatenby P A, Smith H, Kirwan P, Lauer C S. Systemic lupus erythematosus and thrombotic thrombocytopenic purpura-a case report and review of relationship f Rheumatol 1981; 8: 504-8.

4 Cecere F A, Yoshinoya S, Pope R M. Fatal thrombotic thrombocytopenic purpura in a patient with systemic lupus erythematosus. Relationship to circulating immunecomplexes. Arthritis Rheum 1981; 24: 550-3.

5 Dekker A, O'Brien M E, Cammarara $R \mathrm{~J}$. The association of thrombotic thrombocytopenic purpura with systemic lupus erythematosus: a report of two cases with successful treatment of one. Am ₹ Med Sci 1974; 267: 243-9.

6 Laszlo M H, Alvarez A, Feldman F. The association of thrombotic thrombocytopenic purpura and disseminated lupus erythematosus. Report of a case. Ann Intern Med 1955; 42: 1308-20.

7 Levine S, Shearn M A. Thrombotic thrombocytopenic purpura and systemic lupus erythematosus. Arch Intem Med 1964; 113: 826-36.

8 Alpert L I. Thrombotic thrombocytopenic purpura and 
systemic lupus erythematosus. Report of a case with immunofluorescence investigation of vascular lesions. $\mathcal{f}$ Mount Sinai Hosp NY 1968; 35: 165-73.

9 Obeso G, Prieto E, Villalobos E, et al. Purpura trombocitopénica trombótica en paciente afectode lupus eritematoso sistémico. Sangre (Barc) 1987; 32: 83-7.

10 Dixit R, Kriey A M, Atkinson J P. Thrombotic thrombocytopenic purpura developing during pregnancy in a $\mathrm{C} 2$ deficient patient with a history of systemic lupus erythematosus. Arthritis Rheum 1985; 28: 341-4.

11 Fox D A, Faix J D, Coblyn J, Fraser P, Smith B, Weinblatt $M$ E. Thrombotic thrombocytopenic purpura and systemic lupus erythematosus. Ann Rheum Dis 1986; 45: 319-22.

12 Oen K, Petty R E, Schoroeder M L, et al. Thrombotic thrombocytopenic purpura in a girl with systemic lupus erythematosus. F Rheumatol 1980; 7: 727-9.

13 Siegel B M, Friedman I A, Kessler S, Schwartz S O. Thrombohemolytic thrombocytopenic purpura and lupus erythematosus. Ann Intern Med 1957; 47: 1022-9.
14 Ansell J, Reaser R S, Pehcet L. Thrombotic thrombocytopenic purpura fails to respond to fresh frozen plasma infusion. purpura fails to respond to fresh
Ann Intern Med 1978; 89: 647-50.

15 Goodman A, Ramos R, Petrelli M, et al. Gingival biopsy in thrombotic thrombocytopenic purpura. Ann Intern Med 1978; 89: $501-4$.

16 Tan E M, Cohen A S, Fries J F, et al. The 1982 revised criteria for the classification of systemic lupus erythematosus. Arthritis Rheum 1982; 25: 1271-7.

17 Lee S L, Miotti A B. Disorders of hemostatic function in patients with systemic lupus erythematosus. Semin Arthritis Rheum 1975; 4: 251-2.

18 Meuh J R, Herbst K D, Rapaport S I. Thrombosis in patients with the lupus anticoagulant. Ann Intern Med 1980; 92 156-9.

19 Devinsky O, Petito C, Alonso D. Clinical and neuropathological findings in systemic lupus erythematosus: the role of vasculitis, heart emboli and thrombotic thrombocytopenic purpura. Ann Neurol 1988; 23: 380-4. 